\title{
POTENSI ANTIMIKOSIS BEBERAPA TUMBUHAN OBAT INDONESIA
}

\author{
Dewi Kusrini, Khairul Anam, Bambang Cahyono \\ Laboratorium Kimia Organik Jurusan Kimia FMIPA Universitas Diponegoro
}

\begin{abstract}
ABSTRAK
Telah ditelaah potensi antimikosis tumbuhan Annona squamosa L (srikaya), Phylantus Acidus (L) Skeels (ceremai), and Phaleria Macrocarpa [Scheff] Boerl. (mahkota dewa) terhadap mikosis Candida Albicans. Ekstrak etanol srikaya mempunyai aktivitas tertinggi, setara dengan aktivitas $11.566,11 \mu \mathrm{g}$ ketokenazol, dan ekstra etanol mahkota dewa setara dengan 2.344,46 g ketokenazol.

Kata kunci: Annona Squamosa L, Phylantus Acidus (L) Skeels, Phaleria Macrocarpa [Scheff] Boerl

POTENCY OF ANTIMICOSIS FROM SOME INDONESIAN MEDICINAL

PLANTS
\end{abstract}

\begin{abstract}
ABSTRACK
Potency of antimicosis of Annona squamosa L, Phylantus Acidus (L) Skeels, and Phaleria Macrocarpa [Scheff] Boerl. Plants have been analyzed to Candida Albicans. Ethyl alcohol extract of Annona Squamosa have highest activity, equivalent with activity 11.566,11 $\mu \mathrm{g}$ ketokenazol, and ethyl alcohol Phaleria Macrocarpa [Scheff]. Boerl equivalent with 2.344,46 g ketokenazol.

Keywords: Annona Squamosa L, Phylantus Acidus (L) Skeels, Phaleria Macrocarpa [Scheff] Boerl

\section{PENDAHULUAN}

Fungi merupakan salah satu jenis mikroba yang banyak ditemukan di Indonesia. Fungi ini selain bermanfaat di alam sebagai pengurai bahan organik, berperan dalam proses peragian makanan, dan produksi antibiotik, sebagian diantaranya diketahui bersifat patogen bagi tumbuhan. Fungi penyebab penyakit infeksi dikenal sebagai mikosis. Beberapa contoh mikosis diantaranya, Candida penyebab kandidiasis, Aspergillus penyebab aspergilosis, trichhophyton, epidermophyton dan Microsporum penyebab dermatomikosis (Bulmer, 1979, Dalimartha, 1999).

Kerusakan lingkungan hidup menurut UNEP (sebuah lembaga PBB yang bergerak dalam bidang lingkungan hidup) merupakan pemicu timbulnya patogen. Kemunculan patogen ini mendorong timbulnya wabah penyakit infeksi dan menuntut ketersediaan obat-obatan untuk

mengatasinya. Sementara itu obat-obatan yang tersedia relatif sedikit. Amfosterisin B yang sebenarnya bermanfaat untuk mikosis sistemik, mempunyai efek samping menyebabkan kerusakan ginjal. Nistatin yang merupakan antifungi topikal tidak dapat memberikan sistemik. Sementara itu bebrapa obat antibiotik telah diproduksi hingga beberapa generasi. Oleh karena itu upaya pencarian obat baru senantiasa menarik untuk dilakukan.

Tumbuhan obat Indonesia seperti Annona squamosa L (srikaya), Philantus acidus (L) Skeels (ceremai), dan Phaleria macrocarpa [Scheff] Boerl (mahkota dewa) secara tradisional terbukti dapat menyembuhkan berbagai penyakit infeksi seperti TBC, disentri, antraks dan berbagai penyakit kulit (Dalimartha., 1999; Dalimartha, 2003; Goun $d k k$, .2003). Namun informasi/justifikasi ilmiah terhadap bioaktivitas ini belum pernah dilaporkan. Oleh
\end{abstract}


karena itu perlu ditelaah potensi dan aktivitas Annona squamosa L (srikaya), Philantus acidus (L) Skeels (ceremai), dan Phaleria macrocarpa [Scheff] Boerl (mahkota dewa) terhadap mikosis Candida albicans. Serta menentukan golongan kimia komponen penyusun ekstrak aktifnya. Telaah ini bermanfaat untuk memberikan verifikasi ilmiah atas penggunaan tumbuhan tersebut dalam pengobatan tradisional.

\section{METODA PENELITIAN}

Bahan yang digunakan berupa daun srikaya dan kulit batang ceremai yang diperoleh dari Kelurahan Rongtengah, Sampang Madura, serta daun mahkota dewa diperoleh dari sekitar Ungaran, semarang pada bulan Juli 2005. Mikosis uji berupa Candida albicans diperoleh dari PT. Biofarma, Bandung.

\section{Penyiapan Material Uji}

Material uji disortir, dikeringkan dan digiling sehingga menjadi serbuk simplisia. Selanjutnya diektraksi menggunakan pelarut etanol 95\% dan diklorometan. Kedua ekstrak dipekatkan dengan menggunakan rotarivaporator.

\section{Penetapan Kadar Air}

Kadar air ditentukan dengan metode destilasi, sesuai dengan prosedur dalam Farmakope Indonesia IV (Watimena $d k k, 1991)$.

\section{Penyiapan Media Pertumbuhan}

Media pertumbuhan yang digunakan yaitu Nutrient Agar dan Nutrient Broth Sabouraud Dextrose Agar (SDA).

Cara pembuatan SDA dengan melarutkan 65 gram serbuk SDA ke dalam 1 liter air suling dan didihkan selama satu menit hingga semua melarut. Sterilisasi dilakukan dalam autoklaf pada suhu $121^{\circ} \mathrm{C}$ selama 15 menit (Power. and McCuen, 1988).

\section{Sabouraud Dextrose Broth (SDB)}

Cara pembuatan SDB dengan melarutkan 7,5 gram serbuk SDB ke dalam $250 \mathrm{ml}$ air suling dan dididihkan selama satu menit hingga semua melarut. Sterilisasi dilakukan dalam autoklaf pada suhu $121^{\circ} \mathrm{C}$ selama 15 menit (Power. and McCuen, 1988).

\section{Penyiapan Mikroba Uji}

Candida albicans diinokulasikan dalam media pertumbuhan SDA dan diinkubasikan pada suhu $24^{\circ} \mathrm{C}$ selama satu sampai dua hari. Tiap akhir periode inkubasi, fungi uji, Candida albicans, dibuat suspensi persediannya dalam larutan SDB steril. Suspensi fungi diukur kekeruhannya dengan spektrofotometer, pada $\lambda=530 \mathrm{~nm}$ dan transmitannya diatur sehingga didapat $\mathrm{T}=25 \%$, dengan larutan SDB sebagai blanko (Watimena $d k k, 1991)$.

\section{Pengujian Aktivitas Antimikosis}

Pengujian aktivitas antimikosis ekstrak etanol dan ekstrak diklorometana dilakukan dengan metode difusi agar dengan menggunakan cakram kertas sebagai pencadang. Suspensi Candida albicans sebanyak $100 \mu \mathrm{L}$ dicampur ke dalam 10 mL SDA di cawan Petri. Cakram kertas diletakkan diatas media padat tersebut dan ditetesi ekstrak uji $10 \%$ b/v sebanyak $10 \mu \mathrm{L}$. Prainkubasi dilakukan selama 30 menit pada suhu kamar, selanjutnya diinkubasi selama satu sampai dua hari pada suhu $24^{\circ} \mathrm{C}$. Diameter hambat pertumbuhan mikroba uji untuk tiap ekstrak diukur dan pelarut ekstrak digunakan sebagai pembanding (Watimena $d k k, 1991$ ). 


\section{Penapisan Fitokimia}

Penapisan fitokimia bahan meliputi pemeriksaan kualitatif senyawa golongan alkaloid, tanin, saponin, kuinon, flavonoid, dan steroid, triterpenoid (Dalimartha, 2003).

\section{Penetapan Kesetaraan Kekuatan Aktivitas Terhadap Antibiotik Pembanding}

Antibiotik pembanding diencerkan dalam suatu seri konsentrasi dan diuji aktivitasnya terhadap mikroba uji. Cara pengujian sama dengan cara pengujian aktivitasnya antibakteri terhadap ekstrak. Hasil pengujian dibuat suatu persamaan garis antara diameter hambat pertumbuhan mikroba terhadap log konsetrasi antibiotik pembanding.

\section{HASIL DAN PEMBAHASAN}

Untuk menelaah potensi antimikosis tumbuhan obat Indonesia: Annona squamosa L (srikaya), Phyllantus acidus (L) Skeels (Ceremai), dan Phaleria macrocarpa (Scheff) Boerl (mahkota dewa) maka disortasi untuk menghilangkan kotoran atau kontaminan, seperti tanah, debu atau jamur. Proses selanjutnya dilakukan perajangan dan pengeringan. Tujuan dari proses ini untuk menghilangkan air dari simplisia dan memperluas permukaan sel, sehingga dapat menyempurnakan proses ekstrasi setelah dikeringkan, herba tersebut dihaluskan untuk dijadikan serbuk simplasi dan ditentukan kadar airnya. Berdasarkan penentuan kadar air menggunakan metode destilasi diperoleh nilai $8,2 \% ; 6,8 \%$ dan $8,0 \%$ berturut-turut untuk daun srikaya, kulit batang ceremai dan daun mahkota dewa. Hal ini menunjukkan bahwa simplisia kering ini memenuhi ketentuan Farmakope Indonesia VI (1995), yakni maksimal $10 \%$.
Ekstrasi simplisia dilakukan dengan cara maserasi dengan menggunakan pelarut etanol 95 $\%$ dan diklorometana. Sedangkan pemekatan ekstrak dilakukan dengan menggunakan rotarivaporator.

Pengujian aktivitas antimikosis terhadap ekstrak tumbuhan tersebut menggunakan mikosis/fungi uji Candida albicans. Pemilihan mikosis uji berdasarkan mikosis atau fungi yang banyak menyebabkan infeksi atau gangguan kesehatan pada masyarakat.

Beradasarkan hasil pengujian menunjukkan bahwa semua ekstra mempunyai aktivitas antimikosis (Tabel 1). Hal ini ditunjukkan oleh adanya zona hambatan pada area kertas cakram uji.

Tabel 1. Hasil Pengujian Antimikosis Ekstrak Tumbuhan $(10 \% \mathrm{~b} / \mathrm{v})$ Terhadap Candida Albicans

\begin{tabular}{llc}
\hline $\begin{array}{c}\text { Jenis } \\
\text { Tanaman }\end{array}$ & Ekstrak & $\begin{array}{c}\text { Diameter } \\
\text { Hambatan } \\
(\mathbf{m m})\end{array}$ \\
\hline Mahkota & Etanol & $14,7 \pm 1,3$ \\
Dewa & Diklorometana & $12,8 \pm 2,1$ \\
Ceremai & Etanol & $13,6 \pm 2,2$ \\
& Diklorometana & $10,7 \pm 3,1$ \\
\multirow{2}{*}{ Srikaya } & Etanol & $15,6 \pm 3,1$ \\
& Diklorometana & $12,6 \pm 1,2$ \\
\hline
\end{tabular}

Ekstrak etanol dari semua jenis ekstrak tumbuhan mempunyai kemampuan membunuh mikosis lebih kuat, hal ini ditunjukkan dengan nilai diameter hambatannya $(\mathrm{mm})$ yang rata-rata lebih besar daripada ekstrak diklorometana. Nilai hambatan terbesar dimiliki ekstrak etanol srikaya yaitu sebesar 15,6 $\pm 3,1 \mathrm{~mm}$ disusul ekstrak etanol mahkota dewa $(14,7 \pm 1,3 \mathrm{~mm})$ dan ekstrak etanol ceremai $(13,6 \pm 2,2 \mathrm{~mm})$. perbedaan nilai diameter hambatan ini diduga 
karena perbedaan kandungan ekstrak baik secara kualitatif maupun kuantitatif.

Berdasarkan penapisan fitokimia diketahui bahwa ekstrak etanol srikaya, ceremai dan mahkota dewa mempunyai kandungan senyawa kimia seperti diuraikan pada tabel 2 .

Tabel 2. Hasil Penapisan Fitokimia Ekstrak Etanol Tumbuhan Obat

\begin{tabular}{|c|c|c|c|c|c|c|}
\hline \multirow[b]{2}{*}{$\begin{array}{c}\text { Jenis Ekstrak } \\
\text { Etanol }\end{array}$} & \multicolumn{6}{|c|}{$\begin{array}{c}\text { Golongan Senyawa } \\
\text { Kimia } \\
\end{array}$} \\
\hline & 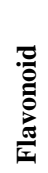 & 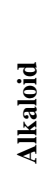 & 葛 & 音 & 葆 & 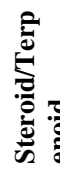 \\
\hline Srikaya & + & + & - & + & + & + \\
\hline Ceremai & + & - & - & + & + & + \\
\hline Mahkota dewa & + & + & - & + & + & + \\
\hline
\end{tabular}

Keterangan :

$+=$ Menunjukkan bahwa ekstrak memberikan hasil positif

- = Menunjukkan bahwa ekstrak memberikan hasil negatif

Kandungan jenis senyawa kimia dalam ketiga ekstrak tumbuhan tersebut relatif sama, yakni mengandung alkaloid, flaonoid, tanin, saponin dan steroid/terpenoid, sedangkan ekstrak etanol ceremai tidak mengandung alkoloid.

Potensi fungisida ekstrak etanol relatif besar terhadap mikosis uji. Potensi terbesar dimiliki oleh ekstrak etanol srikaya, disusul mahkota dewa dan ceremai. Untuk menelaah lebih lanjut potensi antimikosis ini maka perlu dipelajari kesetaraan aktivitasnya dengan antibiotik pembanding.

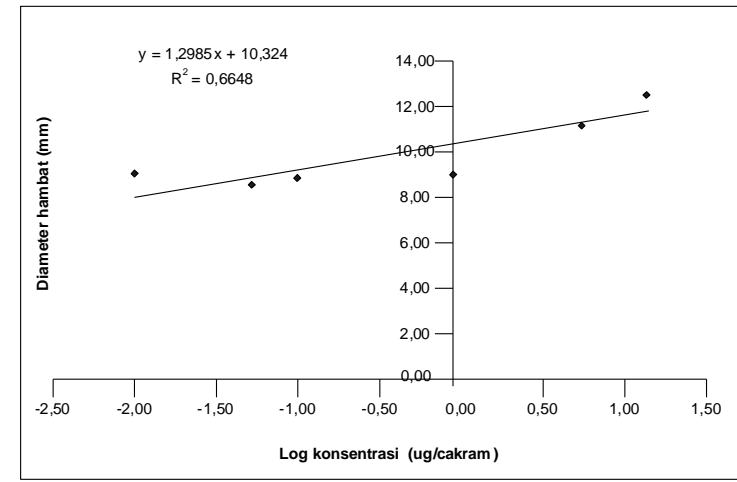

Gambar 1. Kurva Linier Standar Potensi Ketokenazol Terhadap Candida Albicans

Tabel 3 . Kesetaraan $1000 \mu \mathrm{g}$ Ekstrak Terhadap Antibiotik Pembanding Ketokenazol

\begin{tabular}{lc}
\hline $\begin{array}{c}\text { Jenis Ekstrak } \\
\text { Etanol }\end{array}$ & $\begin{array}{c}\text { Kesetaraan Terhadap } \\
\text { Ketokenazol } \boldsymbol{\mu g}\end{array}$ \\
\hline Mahkota Dewa & $2.344,46$ \\
Ceremai & 333,36 \\
Srikaya & $11.565,11$ \\
\hline
\end{tabular}

Pada penataan kesetaraan ekstrak dengan ketokenazol menghasilkan nilai yang beragam (Tabel 3). Nilai terbesar dimiliki oleh ekstrak etanol srikaya, setara dengan 11.566,11 $\mu \mathrm{g}$ ketokenazol. Hal ini menunjukkan bahwa ekstrak etanol srikaya mempunyai aktivitas sangat besar, lebih dari sepuluh kali aktivitas ketokenasol. Demikian pula ekstrak etanol mahkota dewa mempunyai kesetaraan sebesar 2.344,46 $\mu \mathrm{g}$ ketokenasol. Mengingat ekstrak tersusun dari berbagai macam senyawa kimia, maka komponen kimia aktif yang terkandung didalamnya akan mempunyai kekuatan aktivitas antimikosis yang lebih besar lagi. Oleh karena itu tanaman srikaya dan mahkota dewa mempunyai potensi sangat besar untuk dikembangkan dalam pengobatan mengatasi berbagai penyakit yang disebabkan oleh Candida albicans. 


\section{KESIMPULAN}

Berdasarkan penelitian ini dapat disimpulkan:

1. Semua ekstrak etanol dan ekstrak diklorometan Annona squamosa L (srikaya), Phyllantus acidus (L) Skeels (ceremai), dan Phaleria macrocarpa [Scheff] Boerl (mahkota dewa) bersifat fungisida terhadap Candida albicans.

2. Ekstrak etanol Annona squamosa L (srikaya), Phyllantus acidus (L) Skeels (ceremai) dan Phalaria macrocarpa (Scheff) Boerl (mahkota dewa) mempunyai kekuatan fungisida lebih besar dari ekstrak diklorometana.

3. Kesetaraan aktivitas antimikosis terhadap Candida albicans terbesar terhadap antibiotik pembanding, dimiliki oleh ekstrak etanol Srikaya setara 11.565,11 $\mu \mathrm{g}$ ketokenazol dan ekstrak Mahkota dewa setara dengan 2.344,46 $\mu$ g ketokenazol.

\section{DAFTAR PUSTAKA}

Bulmer, G.S., 1979, Introduction to Medical Mycology, Year Book Medical Publisher, Chicago

Dalimartha S., 1999, Atlas Tumbuhan Obat Indonesia, Jilid 1, Trubus Agriwidya, Jakarta

Dalimartha S., 2003, Atlas Tumbuhan Obat Indonesia, Jilid 1, Trubus Agriwidya, Jakarta

Goun. E. Cunningham G., Chu, D., Nguyen, C., Miles, D., 2003, Antibacterial and Antifungal Actovity of Indonesia Ethnomedical Plants, Fitoterapia, 74, 592-6.

Watimena, J.R.R., Sugiarso, N.C., Widianto, M.B., Sukandar, E.Y., Soemarji, AA., dan Setiadi, A.R., 1991, Farmakodonamika dan terapi antibiotik, Gadjah Mada University Press, Yogyakarta. 